\title{
HUBUNGAN IKLIM KOMUNIKASI DENGAN MOTIVASI KERJA PEGAWAI DI BKBPMP KOTA BANJARMASIN
}

\author{
Muhammad Agus Humaidi \\ Universitas Islam Kalimantan Muhammad Arsyad Al-Banjari \\ E-mail: m.agus.humaidi@gmail.com
}

\begin{abstract}
ABSTRAK
Penelitian ini bertujuan untuk mengetahui iklim komunikasi dan motivasi kerja pegawai pada Kantor BKBPMP Kota Banjarmasin, selain itu untuk mengetahui hubungan antara iklim komunikasi dengan motivasi kerja pegawai pada Kantor BKBPMP Kota Banjarmasin. Metode yang digunakan adalah pendekatan penelitian kuantitatif dan instrumen penelitian dengan kuesioner dianalisis dengan Chi Square Goodness Of Fit dan Pearson Correlation. Hasil penelitian menunjukkan bahwa iklim komunikasi pegawai di Kantor BKBPMP Banjarmasin tergolong cukup baik. Sama halnya dengan motivasi kerja pegawai di Kantor BKBPMP Kota Banjarmasin juga termasuk dalam kategori cukup baik. Selain itu, ada hubungan antara iklim komunikasi dengan motivasi kerja pegawai di Kantor BKBPMP Kota Banjarmasin
\end{abstract}

Kata kunci: Iklim Komunikasi; Motivasi Kerja Karyawan. PENDAHULUAN

Suatu organisasi atau instansi pemerintah baik besar maupun kecil bukan semata-mata ditentukan oleh sumber daya alam yang tersedia, akan tetapi banyak ditentukan oleh kualitas sumber daya manusia yang berperan merencanakan, melaksanakan, dan mengendalikan organisasi yang bersangkutan. Oleh karena itu, sumber daya manusia mempengaruhi efisiensi dan efektivitas organisasi dengan merancang dan memproduksi barang dan jasa, mengawasi kualitas, memasarkan produk, mengalokasikan sumber daya financial, serta menentukan seluruh tujuan dan strategi organisasi dan sumber daya manusia merupakan pengeluaran utama organisasi dalam menjalankan tugas-tugasnya (Rachmawati, 2008:1).

Dalam menjalankan tugas-tugas dan tangungjawabnya dengan baik tentunnya pegawai memerlukan komunikasi baik sesama rekan kerja maupun kepada atasannya. Komunikasi berperan penting bagi kelancaran dan keberhasilan suatu organisasi. Liliweri (2004:59-60), mendefenisikan bahwa komunikasi organisasi memproses informasi dan pesan, menafsirkannya dan bertindak berdasarkan informasi.

Sehubungan dengan itu, keberadaan iklim komunikasi organisasi sangatlah penting hal ini disadari oleh Redding dalam Pace dan Faules (2005: 148), ia mengatakan bahwa Iklim komunikasi organisasi jauh lebih penting dari pada ketrampilan atau tehnik-tehnik komunikasi sematamata dalam menciptakan suatu organisasi yang efektif. Iklim komunikasi sebuah organisasi juga dapat mempengaruhi cara hidup kita, kepada siapa berbicara, siapa yang disukai, bagaimana perasaan kita, bagaimana kegiatan kerja kita, bagaimana perkembangan kita, apa yang ingin kita capai dan bagaimana cara beradaptasi dengan organisasi.
Pace dan Faules (2001: 152), menyatakan bahwa alasan lain yang mendukung pentingnya iklim komunikasi organisasi adalah karena dengan adanya iklim komunikasi organisasi yang kondusif, nyaman dan positif, maka dipercaya akan meningkatkan motivasi kerja dari para anggota organisasi atau pegawai tersebut.

Motivasi merupakan "pendorongan" suatu usaha yang disadari untuk mempengaruhi tingkah laku seseorang agar tergerak hatinya untuk bertindak melakukan sesuatu sehingga mencapai hasil atau tujuan tertentu, (Ngalim Purwanto,1998:71). Beberapa faktor yang mempengaruhi motivasi menurut Frederick Herzberg dalam Wibowo (2007:380) yaitu terbagi menjadi dua bagian besar yaitu motivators dan hygiene. Motivators adalah yang sebenarnya mendorong orang untuk mendapatkan kebutuhannya, meliputi prestasi, pengakuan, minat pada pekerjaan, tanggung jawab dan kemajuan. Sedangkan hygiene merupakan kebutuhan dasar manusia, tidak bersifat memotivasi, tetapi kegagalan mendapatkannya menyebabkan ketidakpuasan, yang meliputi gaji dan tunjangan, kondisi kerja, kebijakan organisasi, status kedudukan, keamanan kerja, pengawasan dan otonomi, kehidupan di tempat kerja dan kehidupan pribadi.

Iklim komunikasi dengan motivasi tampaknya memiliki hubungan dengan motivasi kerja hal ini dapat diketahui dari penelitian Dewa Putu Panji Maha Putra (2017), menunjukan terdapat pengaruh antara iklim komunikasi organisasi terhadap motivasi kerja karyawan di Restoran Ranggon Suset Kabupaten Buleleng Bali. Serta dari hasil penelitian Iwan Heru Darmawan (2013), menunjukan adanya hubungan yang sangat signifikan antara iklim komunikasi organisasi 
dengan motivasi kerja karyawan di PT. Media Dian Sejahtera dengan tingkat hubungan kuat. Selain itu hasil penelitian Raymond Soelistiono Filemon (2013), juga menunjukan terdapat pengaruh yang signifikan antara iklim komunikasi terhadap motivasi kerja pada Karyawan PT. PLN (Persero) Area Sidoarjo.

Badan Keluarga Berencana Pemberdayaan Masyarakat dan Perempuan (BKBPMP) merupakan salah satu program Pembangunan Nasional program KB mempunyai arti yang sangat penting dalam upaya mewujudkan manusia Indonesia yang sejahtera disamping program pendidikan dan kesehatan, Undang-Undang No.10 Tahun 1992 tetang Perkembangan Kependudukan dan Pembangunan Keluarga Sejahtera menyebutkan bahwa Keluarga Berencana adalah upaya peningkatan kepedulian dan peran serta masyaraya kat melalui Pendewasaan Usia Perkawinan, Pengaturan Kelahiran, Pembinaan Ketahanan Keluarga serta Peningkatan Kesejahteraan Keluarga untuk mewujudkan Keluarga kecil, bahagia dan sejahtera.

Berdasarkan observasi penelitian di Kantor BKBPMP Kota Banjarmasin peneliti menemukan bahwa hubungan antara atasan dengan bawahan dan hubungan antara pegawai kurang harmonis, misalnya masih kurangnya komunikasi yang efektif antara beberapa pegawai hal ini dapat terlihat dalam pemberian tugas yang diberikan atasan, pegawai lama tidak berperan aktif dalam hal ini untuk memberikan masukan kepada pegawai yang sifatnya masih baru. Selain itu suasana akrab kurang terlihat dan kurang dirasakan dikalangan pegawai, baik dalam hubungan formal maupun informal. Hal ini bisa terlihat dari jarangnya pegawai bertukar fikiran/berdiskusi mengenai pekerjaan dan kekakuan atau kurang ramah, baik dengan sesama pegawai atau dengan tamu.

Dari permasalahan diatas dapat diasumsikan, bahwa kemungkinan permasalahan yang terjadi di Kantor BKBPMP Kota Banjarmasin dipengaruhi iklim komunikasi yang kurang baik. Selain itu, untuk melengkapi hasil kajian tentang hubungan iklim komunikasi dengan motivasi pegawai, hal inilah yang membuat penulis tertarik untuk mengangkat judul skripsi: "HUBUNGAN IKLIM KOMUNIKASI DENGAN MOTIVASI KERJA PEGAWAI DI KANTOR BADAN KELUARGA BERENCANA PEMBERDAYAAN MASYARAKAT DAN PEREMPUAN (BKBPMP) KOTA BANJARMASIN".

\section{TINJAUAN PUSTAKA}

\section{Iklim Komunikasi}

Menurut Pareek dalam Srivastav (2006:125) mengemukakan bahwa iklim komunikasi merupakan hasil dari interaksi antar struktur organisasi, sistem, budaya, tingkah laku pimpinan dan kebutuhan-kebutuhan psikologis karyawan. Definisi lain dikemukakan oleh Moran dan Volkwein dalam McMurray, et al. (2004:474), yang mendefinisikan iklim komunikasi sebagai sebagai persepsi kolektif anggota organisasi tentang organisasinya dengan memperhatikan dimensi-dimensi seperti otonomi, kepercayaan (trust), kekompakan (cohesiveness), dukungan (support), pengenalan (recognition), inovasi dan kewajaran (fairness). Sedangkan Ali Alageh Band dalam Alavi dan Jahandari (2005:250), mendefinisikan iklim komunikasi organisasi sebagai kualitas internal dari sebuah organisasi yang dialami dan dirasakan oleh anggota organisasi.

Penelitian ini menggunakan pendapat Devito untuk mengukur iklim komunikasi pegawai di Kantor BKBPMP Kota Banjarmasin, antara lain : 1) Kepercayaan; 2) Pembuatan keputusan bersama; 3) Kejujuran; 4) Keterbukaan dalam komunikasi kebawah; 5) Mendengarkan dalam komunikasi keatas dan 6) Perhatian pada tujuan-tujuan berkinerja tinggi.

\section{Motivasi}

Motivasi berasal dari kata motivation yang berarti "menggerakkan", motivasi sebagai salah satu unsur penting dalam kepegawaian sebuah lembaga, artinya motivasi kerja dimiliki setiap pegawai. Pegawai dengan motivasi kerja yang optimal tentunya akan melaksanakan pekerjaan yang diberikan dengan sebaik-baiknya dan mengarahkan seluruh kemampuan yang dimilikinya untuk menyelesaikan suatu pekerjaan, motivasi adalah keadaan dalam pribadi seseorang yang mendorong keinginan individu melakukan kegiatan-kegiatan tertentu untuk mencapai tujuan (Handoko, 2002: 252). Sedangkan menurut Buhler (2004: 191), memberikan pendapat tentang pentingnya motivasi sebagai berikut: "Motivasi pada dasarnya adalah proses yang menentukan seberapa banyak usaha yang akan dicurahkan untuk melaksanakan pekerjaan". Motivasi atau dorongan untuk bekerja ini sangat menentukan bagi tercapainya suatu tujuan, maka manusia harus dapat menumbuhkan motivasi kerja setinggitingginya bagi para pegawai dalam organisasi atau lembaga.

Penelitian ini menggunakan pendapat Abraham Maslow untuk mengukur motivasi kerja pegawai di Kantor BKBPMP Kota Banjarmasin, yaitu: 1) Kebutuhan Fisiologis, 2) Kebutuhan Rasa Aman, 3) Kebutuhan Sosial, 4) Kebutuhan Penghargaan dan 5) Aktualisasi diri.

\section{Hubungan Iklim Komunikasi dengan Motivasi Kerja}


Salah satu data pendukung yang menurut peneliti perlu dijadikan bagian tersendiri adalah penelitian terdahulu yang relevan dengan permasalahan yang sedang dibahas dalam penelitian ini. Dalam hal ini, fokus penelitian terdahulu yang dijadikan acuan adalah terkait dengan hubungan iklim komunikasi dengan motivasi kerja. Oleh karena itu, peneliti melakukan langkah kajian terhadap beberapa hasil penelitian berupa jurnal-jurnal melalui internet. Berdasarkan hasil-hasil penelitian yang telah dilakukan menyiratkan bahwa variabel iklim komunikasi memiliki hubungan dengan motivasi seperti hasil penelitian sebagai berikut :

Dewa Putu Panji Maha Putra, meneliti tentang Pengaruh Iklim Komunikasi Organisasi terhadap Motivasi Kerja Karwayan di Restoran Ranggon Suset Kabupaten Buleleng Bali. Hasil penelitian diperoleh nilai thitung untuk variabel iklim komunikasi organisasi (X) sebesar 3,782. nilai ttabel dari tabel distribusi untuk pengujian dua pihak sebesar 2,024. Berdasarkan kreteria uji terliahat bahwa nilai thitung variabel iklim komunikasi organisasi (X) berada pada daerah penolakan H0 $(3,782>2,024)$. Hal ini menunjukan bahwa $\mathrm{H} 0$ ditolak dan $\mathrm{H} 1$ diterima, artinya iklim komunikasi organisasi $(\mathrm{X})$ berpengaruh signifikan terhadap motivasi kerja (Y). Selain itu, Iwan Heru Darmawan, tentang hubungan antara iklim komunikasi organisasi dengan motivasi kerja karyawan di PT Media Dian Sejahtera. Hasil penelitian menunjukan Iklim komunikasi yang ada di dalam perusahaan PT Media Dian Sejahtera terbukti telah mampu memotivasi kerja karyawan. Hal ini didukung melalui perhitungan dan hasilnya terdapat hubungan yang sangat signifikan antara iklim komunikasi dengan motivasi kerja karyawan sebesar 0,770 dengan tingkat hubungan tinggi dan kuat. Serta Raymond Soelistiono Filemon, penelitian tentang Iklim Komunikasi Organisasi Terhadap Motivasi Kerja Karyawan PT. PLN (Persero) Area Sidoarjo. Hasil dari penelitian ini menunjukkan bahwa variabel independen secara simultan berpengaruh positif terhadap variabel dependen.

Uraian di atas secara implisit menunjukkan bahwa iklim komunikasi (variabel X) berpengaruh positif terhadap motivasi kerja (variabel Y) pegawai.

\section{Kerangka Berfikir}

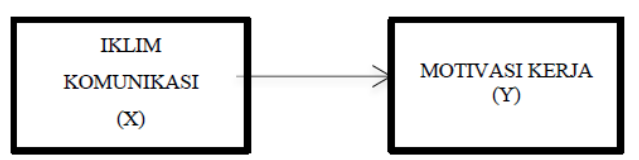

Gambar 2.2. Kerangka Pemikiran Penelitian
Iklim Komunikasi (X) sebagai variabel independen (variabel bebas) mempengaruhi variabel dependen (variabel terikat) Motivasi Kerja (Y).

\section{Hipotesis \\ Hubungan Iklim Komunikasi dengan Motivasi Kerja \\ H0 : Tidak terdapat hubungan antara Iklim Komunikasi dengan Motivasi Kerja pegawai di Kantor BKBPMP Kota Banjarmasin. \\ H1 : Terdapat hubungan antara Iklim Komunikasi dengan Motivasi Kerja pegawai di Kantor BKBPMP Kota Banjarmasin.}

\section{METODE PENELITIAN}

\section{Pendekatan Penelitian}

Dalam melakukan penelitian ini penulis memilih jenis penelitian kuantitatif dengan pendekatan survey.

\section{Tipe Penelitian}

Penulis dalam penelitian ini menggunakan metode penelitian deskriptif dan assosiatif.

\section{Lokasi Penelitian}

Penelitian ini dilakukan di Kantor BKBPMP (Badan Keluarga Berencana Pemberdayaan Masyarakat dan Perempuan) Kota Banjarmasin, dengan objek mencakup Hubungan komunikasi interpersonal dengan motivasi kerja pegawai di Kantor BKBPMP Kota Banjarmasin.

\section{Populasi dan Sampel}

Populasi dalam penelitian ini adalah seluruh pegawai di Kantor BKBPMP Kota Banjarmasin yang berjumlah 96 orang. Dalam penelitian ini hanya sebagian populasi yang diambil untuk dijadikan sampel. Untuk jumlah sampel yang diperlukan rumus slovin. Jadi, Sampel yang akan diambil dalam penelitian ini 77 responden. Skala yang digunakan dalam penelitian ini adalah Skala Likert.

\section{Teknik Pengumpulan Data}

Untuk memperoleh data di Kantor BKBPMP Kota Banjarmasin, khususnya data primer maka dalam penelitian ini digunakan teknik pengumpulan dengan kuesioner (angket).

\section{Definisi Operasional Variabel}

Untuk memperjelas definisi operasional variabel tersebut, peneliti membuat tabel dimana dalam tabel tersebut terdapat bagian kolom variabel, indikator dan parameter. Berikut tabel 3.2. dapat dilihat dibawah ini : 
Tabel 3.2. Definisi Operasional Variabel

\begin{tabular}{|c|c|c|}
\hline Variabel & Indikator & Parameter \\
\hline \multirow[t]{6}{*}{$\begin{array}{l}\text { Iklim Komunikasi adalah suasana yang } \\
\text { tercipta dari interaksi antar struktur sistem } \\
\text { seperti persepsi-persepsi mengenai } \\
\text { peristiwa komunikasi, perilaku manusia, } \\
\text { hubungan dengan anggota, harapan- } \\
\text { harapan, konflik-konflik antarpersona, } \\
\text { dan kesempatan bagi pertumbuhan dalam } \\
\text { organisasi/instansi. }\end{array}$} & a. Kepercayaan; & $\begin{array}{l}\text { - Atasan percaya bahwa pegawai } \\
\text { mampu melaksanakan tupoksi } \\
\text { secara maksimal. } \\
\text { - Pegawai percaya bahwa atasan bisa } \\
\text { bekerja profesional sesuai dengan } \\
\text { tugas dan tanggungjawabnya. }\end{array}$ \\
\hline & $\begin{array}{l}\text { b. Pembuatan keputusan } \\
\text { bersama; }\end{array}$ & 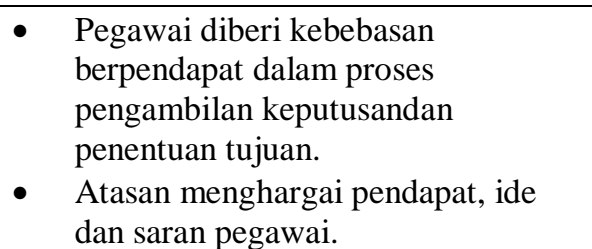 \\
\hline & c. Kejujuran; & $\begin{array}{l}\text { Suasana umum hubungan antara } \\
\text { atasan dengan bawahan maupun } \\
\text { sesama rekan diliputi kejujuran dan } \\
\text { keterusterangan. }\end{array}$ \\
\hline & $\begin{array}{l}\text { d. Keterbukaan dalam } \\
\text { komunikasi kebawah; }\end{array}$ & $\begin{array}{l}\text { - Atasan memberi informasi dan } \\
\text { mensosialisikan tentang kebijakan } \\
\text { kantor pada pegawai. } \\
\text { - Pegawai mendapat informasi yang } \\
\text { beraitan dengan tupoksi dalam } \\
\text { kantor. }\end{array}$ \\
\hline & $\begin{array}{l}\text { e. Mendengarkan dalam } \\
\text { komunikasi keatas; }\end{array}$ & $\begin{array}{l}\text { Informasi yang diterima dari } \\
\text { pegawai dipandang cukup penting } \\
\text { oleh oleh atasan. } \\
\text { - Atasan mendengarkan saran atau } \\
\text { laporan masalah yang diajukan } \\
\text { pegawai }\end{array}$ \\
\hline & $\begin{array}{l}\text { f. Perhatian pada tujuan- } \\
\text { tujuan berkinerja tinggi }\end{array}$ & $\begin{array}{l}\text { - Instansi/lembaga pemerintah } \\
\text { memperhatikan kesejahteraan } \\
\text { pegawai. } \\
\text { - Kantor memberikan pelatihan } \\
\text { kepada pegawai untuk meningkatkan } \\
\text { kemampuan kerjanya. }\end{array}$ \\
\hline \multirow{5}{*}{$\begin{array}{l}\text { Motivasi kerja merupakan suatu keadaan } \\
\text { atau kondisi yang mendorong, } \\
\text { merangsang atau menggerakan seseorang } \\
\text { untuk melakukan sesuatu atau kegiatan } \\
\text { yang dilakukannya sehingga ia dapat } \\
\text { mencapai tujuannya. }\end{array}$} & a. Kebutuhan fisiologis; & $\begin{array}{l}\text { - Makan dan minum agar mendorong } \\
\text { kerja lebih baik. } \\
\text { - Tidur agar bersemangat dalam } \\
\text { bekerja. }\end{array}$ \\
\hline & b. Kebutuhan rasa aman; & $\begin{array}{l}\text { Diberikan asuransi kesehatan agar } \\
\text { mendorong kerja lebih aman. } \\
\text { Memiliki dorongan kerja karena } \\
\text { tunjangan hari tua. }\end{array}$ \\
\hline & c. Kebutuhan sosial; & $\begin{array}{ll}\text { - } & \text { Kerjasama yang kompak dalam } \\
\text { melaksanakan pekerjaan }\end{array}$ \\
\hline & $\begin{array}{l}\text { d. Kebutuhan } \\
\text { penghargaan; }\end{array}$ & $\begin{array}{l}\text { - Memberikan pujian atau hadiah atas } \\
\text { kerja kerasnya }\end{array}$ \\
\hline & e. Aktualisasi diri; & - Inisiatif bekerjanya tinggi \\
\hline
\end{tabular}


MUTAKALLIMIN; Jurnal Ilmu Komunikasi

Vol 4 No 2 November 2021

\section{Analisa Data}

Untuk menjawab rumusan masalah pertama maupun kedua, sekaligus menjawab hipotesis iklim komunikasi dan motivasi kerja dalam penelitian ini menggunakan rumus Chi Square Goodness Of Fit. Sedangkan untuk menjawab rumusan masalah ketiga mengenai hubungan variabel $\mathrm{X}$ dengan variabel $\mathrm{Y}$ digunakan statistik Korelasi Pearson.

\section{HASIL PENELITIAN DAN PEMBAHASAN 1. Iklim Komunikasi Pegawai}

Tabel 4.24. Iklim Komunikasi Pegawai

\begin{tabular}{clcc}
\hline No. & Keterangan & F & \% \\
\hline 1. & Sangat Baik & 2 & 2,6 \\
2. & Baik & 5 & 6,5 \\
3. & Cukup Baik & 48 & 62,3 \\
4. & Kurang Baik & 15 & 19,5 \\
5. & Tidak Baik & 7 & 9,1 \\
\hline & Jumlah & 77 & 100,0 \\
\hline
\end{tabular}

Sumber: Analisa Data Primer 2018

Dari tabel 4.24. tersebut, ternyata kesimpulan disemua kategori iklim komunikasi pegawai di Kantor BKBPMP Kota Banjarmasin, menunjukan bahwa iklim komunikasi pegawai di Kantor BKBPMP Kota Banjarmasin Cukup Baik.

\section{Motivasi Pegawai}

Tabel 4.25. Motivasi Kerja Pegawai

\begin{tabular}{clcc}
\hline No. & Keterangan & F & \% \\
\hline 1. & Sangat Baik & 4 & 5,2 \\
2. & Baik & 16 & 20,8 \\
3. & Cukup Baik & 31 & 40,3 \\
4. & Kurang Baik & 17 & 22,1 \\
5. & Tidak Baik & 9 & 11,7 \\
\hline & Jumlah & $\mathbf{7 7}$ & 100,0 \\
\hline
\end{tabular}

Sumber: Analisa Data Primer 2018

kesimpulan disemua kategori motivasi kerja pegawai di Kantor BKBPMP Kota Banjarmasin, menunjukan bahwa motivasi kerja pegawai di Kantor BKBPMP Kota Banjarmasin Cukup Baik.

\section{Hubungan Iklim Komunikasi}

\begin{tabular}{|c|c|c|c|}
\hline \multicolumn{4}{|c|}{ Correlations } \\
\hline & & $\mathrm{x}$ & Y \\
\hline \multirow[t]{2}{*}{$x$} & Pearson Correlation & 1 &, $453^{\prime \prime}$ \\
\hline & Sig. (2-tailed) & &, 000 \\
\hline & $\mathrm{N}$ & 77 & 77 \\
\hline \multirow[t]{3}{*}{ Y } & Pearson Correlation &, $453^{x x}$ & 1 \\
\hline & Sig. (2-tailed) &, 000 & \\
\hline & $\mathrm{N}$ & 77 & 77 \\
\hline
\end{tabular}

**. Correlation is significant at the 0.01 level (2tailed).

Tabel 4.26. Hubungan Iklim Komunikasi dengan Motivasi Kerja.

Pada tabel 4.26. di atas terlihat bahwa nilai korelasi antara iklim komunikasi dengan motivasi kerja pegawai mempunyai nilai korelasi 0,453 dan nilai probabilitas 0,000. Berdasarkan nilai korelasi 0,453 menunjukan terdapat hubungan atau korelasi antara iklim komunikasi dengan motivasi kerja, korelasi tersebut mempunyai sifat hubungan Sedang. Hasil probabilitas menunjukan bahwa $0,000<0,05$, hal ini menunjukan bahwa $\mathrm{H} 0$ ditolak, dengan demikian hipotesis $\mathrm{H} 1$ yang menyatakan terdapat hubungan antara iklim komunikasi dengan motivasi kerja pegawai di Kantor BKBPMP Kota Banjarmasin diterima. Jadi dapat disimpulkan bahwa apabila iklim komunikasi pegawai membaik maka motivasi kerja pegawai akan ikut membaik, demikian pula sebaliknya bila iklim komunikasi pegawai kurang baik maka motivasi kerja pegawai pun akan kurang baik.

\section{PENUTUP}

\section{Kesimpulan}

Berdasarkan hasil analisis tentang hubungan iklim komunikasi dengan motivasi kerja pegawai di Kantor BKBPMP Kota Banjarmasin maka dapat disimpulkan sebagai berikut:

1) Iklim komunikasi pegawai di Kantor BKBPMP Kota Banjarmasin, yang termasuk kategori Cukup Baik sebanyak 48 orang $(62,3 \%)$, sedangkan yang kategori Kurang Baik sebanyak 15 orang (19,5\%), kategori Tidak Baik 7 orang $(9,1 \%)$, sama dengan kategori Baik 5 orang $(6,5 \%)$ dan ada 2 orang $(2,6 \%)$ yang termasuk kategori Sangat Baik. Hal ini menunjukan bahwa iklim komunikasi pegawai di Kantor BKBPMP Kota Banjarmasin Cukup Baik.

2) Motivasi kerja pegawai di Kantor BKBPMP Kota Banjarmasin, yang termasuk dalam kategori Cukup Baik sebanyak 31 orang (40,3\%), sedangkan kategori Kurang Baik sebanyak 17 orang $(22,1 \%)$, sedangkan kategori Baik 16 orang (20,8\%), kategori Tidak Baik sebanyak 9 orang $(11,7 \%)$, dan hanya ada 4 orang $(5,2 \%)$ yang termasuk kategori Sangat Baik. Hal ini menunjukan bahwa motivasi 
kerja pegawai di Kantor BKBPMP Kota Banjarmasin Cukup Baik.

3) Iklim komunikasi dengan motivasi kerja pegawai mempunyai nilai korelasi 0,453 dan nilai probabilitas 0,000. Berdasarkan nilai korelasi 0,453 menunjukan terdapat hubungan atau korelasi antara iklim komunikasi dengan motivasi kerja, korelasi tersebut mempunyai sifat hubungan Sedang. Hasil probabilitas menunjukan bahwa $0,000<0,05$, hal ini menunjukan bahwa H0 ditolak, dengan demikian hipotesis $\mathrm{H} 1$ yang menyatakan terdapat hubungan antara iklim komunikasi dengan motivasi kerja pegawai di Kantor BKBPMP Kota Banjarmasin diterima. Jadi dapat disimpulkan bahwa apabila iklim komunikasi pegawai membaik maka motivasi kerja pegawai akan ikut membaik, demikian pula sebaliknya bila iklim komunikasi pegawai kurang baik maka motivasi kerja pegawai pun akan kurang baik.

\section{Saran}

Dari kesimpulan yang telah dikemukakan berdasarkan hasil analisis yang diperoleh maka ada beberapa saransaran yang perlu dijadikan pertimbangan yaitu:

1) Berdasarkan hasil analisis tingkatan iklim komunikasi pegawai berada pada kategori Cukup Baik. Hal ini menandakan masih adanya iklim komunikasi pegawai yang rendah. Maka dari itu hendaknya di Kantor BKBPMP Kota Banjarmasin selalu meningkatkan iklim komunikasi pegawainya.

2) Dari hasil analisis motivasi kerja pegawai termasuk pada kategori Cukup Baik. Hal ini menandakan masih terdapat pegawai yang kurang dorongan atau motivasi dalam melaksanakan dan menyelesaikan pekerjaannya. Oleh karena itu, diharapkan di Kantor BKBPMP Kota Banjarmasin terus memberikan atau meningkatkan motivasi kerja pegawainya.

3) Dengan adanya hubungan antara iklim komunikasi dengan motivasi kerja pegawai, hendaknya semua pegawai di Kantor BKBPMP Kota Banjarmasin terus mengoptimalkan iklim komunikasi pegawainya dengan sempurna agar berdampak terhadap peningkatan motivasi kerja pegawainya yang maksimal.

\section{REFERENSI}

\section{Buku}

Elliot et al. 2000. Educational Psychology: Efective Teaching, Effective Learning, 3rd edition. United States of America: Mc Graw Hill Companies.

Buhler, Patricia. 2004. Alpa Teach Yourself. Management Skills dalam 24Jam. Jakarta: Prenada Media.

Hamzah, B. Uno. 2007. Teori Motivasi Dan Pengukuran: Analisis di Bidang Pendidikan. Jakarta: Bumi Aksara.

Handoko, T. Hani. 2002. Manajemen Personalia dan Sumber Daya Manusia. Yogyakarta: BPFE YOGYAKARTA.

Kriantono, Rahmat. 2006. Riset Komunikasi. Jakarta:
Kencana Prenada Media Group.

Liliweri, A. 2004. Wacana Komunikasi Organisasi. Bandung: PT. Mandar Maju.

Mangkunegara, Anwar Prabu . 2005. Manajemen Sumber Daya Manusia Perusahaan. Bandung: Remaja Rosdakarya.

Marwansyah dan Mukaram. 2000. Manajemen Sumber Daya Manusia. Bandung: Pusat Penerbitan Administrasi Niaga.

Masmuh, Abdullah. 2008. Komunikasi Organisasi Dalam Perspektif Teori dan Praktik. Malang: UPT Universitas Muhammadiyah Malang. Muhammad, A. 2011. Komunikasi Organisasi. Jakarta: Bumi Akasara.

Mulyana, D. 2001. Ilmu Komunikasi Suatu Pengantar. Cetakan Ke-14. Bandung: PT Remaja Rosdakarya.

Mulyasa, E. 2003. Kurikulum Berbasis Kompetensi. Bandung: Remaja Rosdakarya.

Ngalim, P. 1998. Pisikologi Pendidikan. Bandung: PT. Remaja Rosdakarya.

Pace, R. Wayne. and Don, F. Faules. 2005. Komunikasi Organisasi: Strategi Meningkatkan Kinerja Perusahaan. Mulyana D, Kuswarno E, Gembirasari, penerjemaah. Mulyana D, editor. Bandung: PT. Remaja Rosdakarya. 2001.

Komunikasi Organisasi-Strategi Meningkatkan Kinerja Perusahaan. Mulyana D, Kuswarno E, Gembirasari, penerjemaah. Mulyana D, editor. Bandung: PT. Remaja Rosdakarya.

Robbin, Stephen P. dan Judge Timothy A. 2008. Perilaku Organisasi Jilid 2. Jakarta: Salemba Empat.

Romli, Khomsahrial. 2011. Komunikasi Organisasi Lengkap. Jakarta: PT Grasindo.

Samsudin, S. 2005. Manajemen Sumber Daya Manusia. Bandung: Pustaka Setia.

Sardiman. 2006. Interaksi dan Motivasi Belajar Mengajar. Jakarta: Rajawali Pers.

Siagian, Sondang P. 2002. Administrasi Pembangunan. Jakarta: Bumi Aksara.

Sugiyono. 2012. Metode Penelitian Pendidikan (Pendekatan Kuantitatif, Kualitatif dan $R \& D$ ). Bandung: ALFABETA.

Usman, M. Uzer. 2000. Menjadi Guru Profesional. Bandung: Remaja Rosdakarya.

Wibowo. 2007. Manajemen Kinerja. Jakarta: PT. Raja Grafindo Persada.

Winardi. 2007. Motivasi Dan Pemotivasian Dalam Manajemen. Jakarta: PT. Grafindo Persada.

\section{Jurnal}

Iwan Heru Darmawan. 2013. Hubungan antara iklim komunikasi organisasi dengan motivasi kerja karyawan di PT Media Dian Sejahtera. Jurnal Visi Komunikasi. Vol. 12, No. 2

McMurray, Adela J., D.R. Scott and R. W. Pace. 2004. The Relationship between Organizational Commitment and Organizational Climate in Manufacturing. Human Resource Development 
MUTAKALLIMIN; Jurnal Ilmu Komunikasi

Vol 4 No 2 November 2021

Quarterly, Vol. 15, No.4

Panji Maha Putra D, P. 2017. Pengaruh Iklim

Kerja Karwayan di Restoran Ranggon Suset Kabupaten Buleleng Bali. e-Proceeding of Management. Vol.4, No.3

Soelistiono Filemon R. 2013. Pengaruh Iklim

Komunikasi Organisasi Terhadap Motivasi

Kerja Karyawan PT. PLN (Persero) Area

Sidoarjo. Jurnal Interaksi Online. Vol. 1, No. 4

Mulyana, D. 2001. Ilmu Komunikasi Suatu Pengantar. Cetakan Ke-14. Bandung: PT Remaja Rosdakarya.

Mulyasa, E. 2003. Kurikulum Berbasis Kompetensi. Bandung: Remaja Rosdakarya.

Ngalim, P. 1998. Pisikologi Pendidikan. Bandung: PT. Remaja Rosdakarya.

Pace, R. Wayne. and Don, F. Faules. 2005. Komunikasi Organisasi: Strategi Meningkatkan Kinerja Perusahaan. Mulyana D, Kuswarno E, Gembirasari, penerjemaah. Mulyana D, editor. Bandung: PT. Remaja Rosdakarya. 2001.

Komunikasi Organisasi-Strategi Meningkatkan Kinerja Perusahaan. Mulyana D, Kuswarno E, Gembirasari, penerjemaah. Mulyana D, editor. Bandung: PT. Remaja Rosdakarya. Robbin, Stephen P. dan Judge Timothy A. 2008. Perilaku Organisasi Jilid 2. Jakarta: Salemba Empat.

Romli, Khomsahrial. 2011. Komunikasi Organisasi Lengkap. Jakarta: PT Grasindo.

Samsudin, S. 2005. Manajemen Sumber Daya Manusia. Bandung: Pustaka Setia.

Sardiman. 2006. Interaksi dan Motivasi Belajar Mengajar. Jakarta: Rajawali Pers.

Siagian, Sondang P. 2002. Administrasi Pembangunan. Jakarta: Bumi Aksara.

Sugiyono. 2012. Metode Penelitian Pendidikan (Pendekatan Kuantitatif, Kualitatif dan $R \& D)$. Bandung: ALFABETA.

Usman, M. Uzer. 2000. Menjadi Guru Profesional. Bandung: Remaja Rosdakarya.

Wibowo. 2007. Manajemen Kinerja. Jakarta: PT. Raja Grafindo Persada.

Winardi. 2007. Motivasi Dan Pemotivasian Dalam Manajemen. Jakarta: PT. Grafindo Persada.

Komunikasi Organisasi terhadap Motivasi 